INVESTIGACIÓN

http://doi.org/10.15198/seeci.2019.50.43-72

Recibido: 31/05/2019 --- Aceptado: 26/06/2019 --- Publicado: 15/11/2019

\title{
COMPETENCIAS CLAVES DE LOS ESTUDIANTES UNIVERSITARIOS PARA EL USO DE LAS TIC
}

\section{KEY COMPETENCES OF UNIVERSITY STUDENTS FOR THE USE OF ICT}

\begin{abstract}
(iD) $\mathbb{R}^{6}$ María Eugenia Bello van der Ree ${ }^{\mathbf{1}}$ : Universidad Metropolitana. Venezuela. mabello@unimet.edu.ve
\end{abstract}

(i) 1 Juan Antonio Morales Lozano: Universidad de Sevilla. España. jamorales@us.es

\section{RESUMEN}

El objetivo del presente trabajo es describir el perfil de competencias claves que requiere el estudiante universitario de la carrera de Pedagogía para el uso de las Tecnologías de la Información y la Comunicación, en la ciudad de Caracas, Venezuela. La metodología consiste en un estudio de campo, descriptivo, ex post facto, transversal. Se presenta un listado de 54 competencias a estudiar, para lo cual se logró la participación de veintinueve docentes, treinta empleadores y trescientos ochenta y cinco estudiantes durante un período de nueve meses en seis universidades. Para el análisis de los datos se utilizó un enfoque mixto, en parte cuantitativo y en parte cualitativo, es decir estadística descriptiva, frecuencia y porcentaje para las preguntas cerradas, y para las preguntas de carácter abierto se llevó a cabo un análisis de contenido de acuerdo a su relación con el marco teórico, con el objeto de describir las competencias de los estudiantes para el uso de las Tecnologías de la Información y la Comunicación. Los resultados generales señalan que las tres muestras consideran en su mayoría las competencias como muy importantes, encontrando algunas diferencias en cuanto al desarrollo de las mismas. El estudio de correlaciones entre las poblaciones refleja que hay similitudes en cuanto a la tendencia como perciben las competencias, pero sin ninguna correlación entre las poblaciones. Por lo que se considera que los resultados son coherentes en el sentido de que todos dicen exactamente lo mismo. Finalmente, se presenta propuesta de perfil de competencias claves que requiere el estudiante de la carrera de Pedagogía para el manejo de las TIC, el cual podría ser considerado en futuros diseños de planes de estudio y programas de formación de docentes.

${ }^{1}$ María Eugenia Bello van der Ree: Actualmente es Decana de Formación General y Básica, fue Directora de la Escuela de Educación en la Universidad Metropolitana en Caracas, Venezuela.

mabello@unimet.edu.ve 
Bello van der Ree, M. E. y Morales Lozano, J. A. Competencias claves de los estudiantes universitarios para el uso de las TIC

PALABRAS CLAVE: perfil - competencias - Tecnologías de Información y Comunicación - currículum - plan de estudio - estudiantes - diseño curricular.

\section{ABSTRACT}

The objective of the present study is to describe the profile of key competences required by the University student of pedagogy for the use of the technologies of information and communication, in the city of Caracas, Venezuela. The methodology consists of a descriptive field study, ex post facto, cross. It is a list of 54 skills to study, for which the participation of twenty-nine teachers, 30 employers and three hundred and eighty-five students was achieved over a period of nine months at six universities. A mixed, partly quantitative and some qualitative approach was used for the analysis of the data as well as descriptive statistics in order to describe the competence of students for the use of the Information and communication technologies. The overall results indicate that three samples mostly considered as very important competencies, finding some differences in the development of the same. The study of correlations between populations reflects that there are similarities in the trend as they perceive competitions, but no correlation between populations. It is considered that the results are consistent in the sense that all say exactly the same. Finally, there is motion for a competency profile key that requires the student of pedagogy for the management of ICT, which could be considered in future designs of curricula and teacher training programs.

KEY WORDS: profile - competences - Information and Communication Technologies - curriculum - plan of study - students - curriculum design.

\section{HABILIDADES CHAVES DOS ESTUDANTES UNIVERSITARIOS PARA O USO DE TIC}

\section{RESUME}

O objetivo do presente trabalho e descrever o perfil de habilidades chaves que requer o estudante universitário da matéria de Pedagogia para o uso das Tecnologia da Informação e da Comunicação, na cidade de Caracas, Venezuela. A metodologia consiste em um estudo de campo, descritivo, ex post fato, transversal. Se apresenta uma lista de 54 habilidades a estudar, para o qual logrou a participação de 29 docentes, 30 empregados e 385 estudantes durante um período de 9 meses em 6 universidades. Para a analises dos dados se utilizo um enfoque misto, em parte quantitativo e em parte qualitativo, que dizer estadística descritiva, frequência e porcentagem para as perguntas fechadas, e para as perguntas de caráter aberto foi feito um analise de conteúdo de acordo a sua relação com o marco teórico, com o objetivo de descrever as habilidades dos estudantes para o uso das Tecnologias da Informação e Comunicação. Os resultados gerais assinalam que as três amostras consideram em sua maioria as habilidades como muito importantes, encontrando algumas diferenças enquanto ao desenvolvimento das mesmas. O estudo de correlações entre as populações reflete que há similitudes enquanto a tendência como percebem as habilidades, mas sem nenhuma correlação entre as populações. 
Bello van der Ree, M. E. y Morales Lozano, J. A. Competencias claves de los estudiantes universitarios para el uso de las TIC

Pelo que se considera que os resultados são coerentes no sentido de que todos dizem exatamente 0 mesmo. Finalmente, se apresenta proposta de perfil de habilidades chaves que requer o estudante de Pedagogia para o manejo das T.I.C., o qual poderia ser considerado em futuros desenhos de planos de estudo e programas de formação de docentes.

PALAVRAS CHAVE: perfil - habilidades - TIC - curriculum - plano de estudo estudantes - desenho curricular.

\section{Cómo citar el artículo:}

Bello van der Ree, M. E. y Morales Lozano, J. A. (2019). Competencias claves de los estudiantes universitarios para el uso de las TIC. [Key competences of university students for the use of ICT]. Revista de Comunicación de la SEECI, (50), 43-72. doi: http://doi.org/10.15198/seeci.2019.50.43-72

Recuperado de http://www.seeci.net/revista/index.php/seeci/article/view/603

\section{INTRODUCCIÓN}

La llegada de las tecnologías educativas determina una formación de un estudiante con un perfil diferente, con un nuevo diseño del modelo educativo, pues ellas están impactando directamente a la sociedad, específicamente al individuo y su desenvolvimiento diario y cotidiano en la vida, esto incluye el plano laboral y el personal. En materia de tecnología el avance mundial es enorme, creamos naves espaciales, biotecnología, ingeniería genética, rayos láser, satélites, supercomputadoras, TV interactiva, ingeniería artificial, nano tecnología, impresoras $3 \mathrm{D}$, juegos de realidad virtual, pantallas táctiles, teléfonos inteligentes, lo que nos lleva a analizar ¿Qué ha sucedido con la Educación?, ¿Qué cambios son necesarios?, ¿Cuáles son los nuevos planteamientos educativos?, ¿Cuáles son las competencias que requiere el usuario para el uso de la tecnología?

Los incesantes avances científicos en todos los ámbitos de conocimiento y sus correspondientes desarrollos tecnológicos, nos están brindando nuevos y poderosos instrumentos para realizar nuestros trabajos. Los avances en la ciencia y la tecnología que podrían cambiar nuestras vidas como coches sin conductor o la ingeniería genética, es necesario tenerlos presente cuando se diseñan planes de estudio.

Autores como Govantes, 2001; Cabero et al. 2000; Castañeda, s/f; Belloch, 2000; BBC, 2018; coinciden en que todos estos cambios y transformaciones, que se ha producido de manera tan rápida en todos los campos de la vida moderna es algo que caracteriza al mundo en que vivimos.

Aquellas personas que no tengan las competencias básicas en TIC, es decir, que no conozcan cómo leer a través de las fuentes de información digitales como son páginas web, canales de TV, ciberbibliotecas, mediatecas, entre otras, así como no sepan escribir con los editores de texto o comunicarse a través de los canales 
Bello van der Ree, M. E. y Morales Lozano, J. A. Competencias claves de los estudiantes universitarios para el uso de las TIC

telemáticos, uso de la Web 2.0, se considerarán analfabetas, y estarán en desventaja para desenvolverse en la sociedad y en sus diferentes profesiones, especialmente los docentes que necesitarán de estas competencias para su práctica pedagógica.

De ahí la importancia de que las universidades tomen en cuenta la alfabetización digital y la integración de las TIC en los planes de estudio, de manera que sus egresados logren su participación en todos los estamentos políticos, económicos y sociales, acordes con los retos de nuestra sociedad.

Autores como Cabero, J., Castaño, C., Cebreiro, B., Gisbert, M., Martínez, F., Morales, J., Prendes, M., Romero, R. y Salinas, J. (2003); Belloch (2000), y Cabero (2003), así como en el Informe Horizon (2017), concuerdan en que el papel del estudiante es de un individuo autónomo que investiga y reflexiona sobre su proceso de enseñanza-aprendizaje. Agregando que los alumnos, necesitan de una alfabetización digital que le permita utilizar de manera eficaz y eficiente estos nuevos instrumentos tecnológicos que conforman las TIC en sus actividades como estudiante y como futuro profesional. Por lo que necesita de competencias instrumentales para usar los programas y los recursos de Internet, pero aún más relevante es el hecho de que el estudiante de Educación, requiere de competencias didácticas para el uso de las TIC en sus diferentes roles profesionales que le tocará vivenciar.

La formación de los alumnos en relación al uso de las nuevas tecnologías requiere clarificar las políticas y programas elaborados para tal fin y además enmarcarlos en las instituciones de formación superior, de una sociedad cambiante, en donde se afronte la concepción del estudiante y su nuevo perfil atendiendo a la demanda de integración de las TIC en el contexto educativo.

Alva (2003), así como Ojeda, Pino-Juste y Soto (2017) y García y Lorente (2017) agregan que el estudiante debe ser ahora un elemento activo en el proceso de adquisición del conocimiento. El nuevo modelo educativo es importante que tenga como eje central del aprendizaje: la motivación, la resolución de problemas y el trabajo colaborativo. La habilidad de trabajar en grupo, en base a proyectos definidos son también de gran importancia en el nuevo contexto económico y social.

El estudiante en el siglo XXI deberá ser:

- Responsable de su propio proceso de aprendizaje.

- Un individuo participativo y colaborativo.

- Un individuo con capacidad de autorreflexión y generador de conocimiento.

En relación a la fundamentación en cuanto a las Tecnologías de la Información y la Comunicación, se hizo revisión del concepto, sus características, sus ventajas e inconvenientes, las políticas en Venezuela en relación al tema, los medios aplicados a la educación, seguimiento y evolución, para ello se tomaron en cuenta autores como García y Lorente (2017); Castaño (Coord., 2009); Cabero (2001, 2006, 2007, 2008); Cabero y Gisbert (2008); Cabero, Salinas, Duarte, Domingo (2000); Sevillano (2002); López (2001); Area (2002); García (2001); Valdés (2000); Escudero (2004); Cabero, Castaño, Cebreiro, Gisbert, Martínez, Morales, Prendes, Romero y Salinas (2003); 
Bello van der Ree, M. E. y Morales Lozano, J. A. Competencias claves de los estudiantes universitarios para el uso de las TIC

Martínez (2003); Área (2004); Bello y Morales (2007); Romero (2008); Aguaded y Contín (2002); Joa (2003); Duarte (2002); Ibáñez (2003); Parra (2003); Andrade y Gómez (2007).

García, Tobón y López (2009) señalan la importancia que ha venido cobrando el enfoque de competencias en la Educación Superior, alrededor del cual gira la gestión de la calidad, siendo el mismo la base de los procesos de formación, investigación y extensión universitaria. De allí que cada vez se observan proyectos de cambios, en donde el término competencias es parte de las reformas y transformaciones del currículum, el aumento de publicaciones, seminarios y postgrados en el área.

Por esto se observa que en muchos países se vienen llevando a cabo una serie de reformas educativas y políticas públicas, en donde se toman en cuenta todos los factores e influencia que traen consigo la inclusión de las Tecnologías de la Información y la Comunicación en los procesos de formación. Autores como García, Reyes y Godínez (2017); Castañón y Aguilar (2017); Cabero et al. (2002, 2003); Cabero (2003); Majo y Marquès (2002); Belloch (2000); Duarte (2002); Martínez, Pérez, Granda, y Sanpedro (2002); entre otros, han puesto de manifiesto los efectos positivos y facilitadores que derivan esta integración.

Es evidente que la informática en el ámbito educativo va en aumento y es necesario investigar para poder señalar las bases que permitan un desarrollo armónico y fundamentado pedagógicamente. Es recomendable que los estudiantes, vean la cantidad de posibilidades que las Tecnologías de Información y Comunicación ofrecen durante su proceso de formación y en su posterior desempeño profesional.

En Venezuela, hasta el 2015, se ha venido experimentando un crecimiento sostenido de usuarios conectados a Internet, hecho que se observa en las declaraciones del director general de la Comisión Nacional de Telecomunicaciones (Conatel) William Castillo, señalando que para el segundo trimestre de 2015, se cuenta con 16 millones 400 mil usuarios, equivalentes al $61,62 \%$ de la población nacional, y superando la media mundial de $43 \%$. Datos presentados, en una mesa de trabajo que sostuvo con periodistas de la fuente (El Universal, 2015). Actualmente, en el año 2019, en Venezuela se tienen muchas dificultades para estar conectados con Internet, debido a la falta de mantenimiento y actualización de equipos por parte de la empresa estatal de telecomunicaciones CANTV. Son muchos los hogares a los que les resulta imposible poder conectarse y navegar por las distintas redes. Lo que utiliza el ciudadano son los planes de la telefonía móvil, a través de los datos se comunican principalmente a través de las redes sociales, como son WhatsApp, Instagram, Twitter, Facebook, entre otras.

Así mismo, otro estudio sobre las tendencias digitales de los venezolanos en el 2015, señala que cada vez estamos en un mundo más conectado y los medios digitales seguirán creciendo, no tanto en penetración poblacional sino en exposición en horas y uso, cada vez estamos más expuestos a Internet mediante el uso de diversas pantallas, ganando influencia en la toma de decisiones de los consumidores. Se recogen como principales tendencias el uso de Internet a través de los medios 
sociales, el uso de más imágenes y menos palabras, se observa que los usuarios además de publicar contenidos, cada vez colaboran más entre sí para obtener beneficios, hay más dispositivos conectados que personas, los dispositivos móviles se utilizan más para conectarse a la Red, crecen las transacciones online, aumenta la data debido a tantas personas y dispositivos conectados (Jiménez, 2015). Actualmente, señalan en la página de Tendencias Digitales que la penetración en Internet y sobre todo de los dispositivos móviles han ha ido cambiando dando mayor relevancia a los medios digitales, especifican que en el 2018 el $66 \%$ de los latinoamericanos tiene acceso a Internet y el $58 \%$ se conectan utilizando sus teléfono móviles (Tendencias Digitales, 2019).

Resultados que ponen de relevancia los cambios, que cada vez son más necesarios en los planes de estudio en la Educación Superior, así como en las metodologías de enseñanzas que contribuyan con la incorporación de las tecnologías en los procesos de formación por competencias. Datos que llevan a las universidades venezolanas a replantearse la forma en cómo se realizan los procesos de enseñanzaaprendizaje, reorientar su filosofía educativa a favor de nuevos modelos en donde se vean reflejados el proceso de globalización económica, el desarrollo tecnológico y los avances de la Didáctica. Tal como señalan Cabero y Llorente (2006) y Alfonso (2016), las transformaciones que se están produciendo en nuestra cultura, por el paso de la Sociedad Industrial a la Sociedad de la Información, conllevan desde el punto de vista educativo que se realicen nuevos procesos de alfabetización utilizando formas innovadoras de enseñar y de aprender. De aquí que tanto los estudiantes como los docentes, necesitan tener en cuenta nuevas competencias y habilidades tecnológicas para poder dar respuesta a las exigencias que están apareciendo en el ámbito socioeducativo. Igualmente Cabero (2007), señala algunas medidas que pueden facilitar la incorporación de las TIC en el currículum. Las sintetiza en la presencia de los propios centros, transformación respecto a las concepciones que se tienen sobre la enseñanza, la formación de los docentes, cambio del currículo, alfabetización informática-mediática, y la organización y gestión en las instituciones.

Otro elemento a considerar es la Educación desde la dimensión de la formación a lo largo de la vida, que se ha venido imponiendo como una necesidad y realidad, y en donde las Tecnologías de la Información y la Comunicación juegan un papel importante (Belando-Montoro, 2017). Aprender a lo largo de la vida, señala Morales (2010) "...es una necesidad consecuencia de los innumerables cambios a los que debemos hacer frente..." (p. 1) y agrega que la Educación desde la visión del aprendizaje permanente, cobra protagonismo y se convierte en una pieza clave para el desarrollo de las sociedades actuales, las sociedades de la información y del conocimiento. (Morales, 2010).

Es muy importante en la formación de docentes, que se tomen en cuenta los planteamientos y problemas actuales, lo que origina la necesidad de revisar los planes de estudios y adecuarlos a las necesidades, tanto en Venezuela como en el mundo, de modo que den respuesta a cuales son las competencias más relevantes que se recomienda desarrollar en los mismos y que permitan generar procesos 
Bello van der Ree, M. E. y Morales Lozano, J. A. Competencias claves de los estudiantes universitarios para el uso de las TIC

educativos en los estudiantes de Educación para el uso de las Tecnologías de la Información y la Comunicación en su práctica pedagógica.

Las TIC proporcionan recursos didácticos que pueden ayudar a los profesores en el desarrollo de sus actividades, de allí la importancia de tener esto presente para el diseño de planes de estudio en la Educación Superior (Aguilar, Bello, Castañón, Martínez, Garassini y García, 2007).

Por otro lado, como señala Chan (2005) y lo comparte Morales, García, Campos y Astroza (2013), el desarrollo de nuevas competencias por parte de los sujetos para relacionarse con objetos de conocimiento en entornos digitales se percibe como parte de un fenómeno de transformación de las prácticas educativas, por la incorporación de las Nuevas Tecnologías de la Información y la Comunicación. Lo que lleva a reflexionar sobre qué tipo de competencias hablamos: ¿Se trata de nuevas competencias cognitivas?, ¿O acaso de nuevas competencias comunicativas?, o será que ¿Los docentes requieren unas competencias didácticas especiales? ¿Será que los docentes y empleadores conocen las competencias que requieren sus alumnos? Y los estudiantes, ¿Qué nuevas competencias necesitan?, ¿Serán todas estas en conjunción?, ¿Cuáles serán?, ¿Los estudiantes serán conscientes de las competencias que se requieren para dominar el uso de las Tecnologías de la Información y la Comunicación?

Un primer paso para potenciar el conocimiento de las competencias claves para el uso de las Tecnologías de la Información y la Comunicación puede ser la exploración y el análisis de la realidad más inmediata de los estudiantes universitarios de la carrera de Pedagogía: ¿Están los estudiantes universitarios incorporando la tecnología informática y audiovisual?, ¿Mejora con estos recursos el proceso de aprendizaje?, ¿Con qué dificultades o limitaciones en recursos se encuentra el estudiante?, ¿De qué formación dispone en la utilización de las TIC como estudiante?, ¿Cuáles son las competencias claves más apremiantes?, entre otras inquietudes. A través de esta investigación se pretende dar respuesta a ¿Cuáles serán las competencias claves que requiere el estudiante universitario para el uso de las Tecnologías de la Información y la Comunicación?

\section{OBJETIVOS}

La existencia de las Tecnologías de la Información y la Comunicación en la Educación han provocado la aplicación de nuevas estrategias didácticas en el proceso de enseñanza-aprendizaje, de acuerdo a las demandas de la Sociedad de la Información, así como los cambios que se vienen realizando a nivel de los planes de estudio en Educación Superior, en especial en la carrera de Pedagogía, en términos de competencias, y con el fin de dar respuesta a las interrogantes presentadas anteriormente, nos planteamos como objetivo general describir el perfil de competencias claves que requiere el estudiante universitario de la carrera de Pedagogía para el uso de las Tecnologías de la Información y la Comunicación (TIC), en la ciudad de Caracas. 
Bello van der Ree, M. E. y Morales Lozano, J. A. Competencias claves de los estudiantes universitarios para el uso de las TIC

Y como objetivos específicos se pretendió:

- Indagar las competencias que tienen los estudiantes universitarios de la carrera de Pedagogía para el manejo de las TIC.

- Conocer la opinión que tienen los docentes universitarios de la carrera de Pedagogía sobre las competencias que requieren los estudiantes para el uso de las TIC.

- Explorar la opinión que tienen los empleadores en relación a las competencias que requieren los estudiantes egresados de la carrera de Pedagogía para el uso de las TIC.

- Identificar diferencias significativas en cuanto a la importancia y el desarrollo de las competencias entre la opinión de los docentes, empleadores y estudiantes.

- Proponer el perfil de competencias claves que requiere el estudiante de la carrera de Pedagogía para el manejo de las TIC.

Una variada revisión bibliográfica nos permite concretar un concepto de competencia, apuntando a un conjunto de conocimientos, habilidades, actitudes y valores que requieren de manera integral movilizar los estudiantes universitarios de la carrera de Educación, para utilizar las Tecnologías de la Información y la Comunicación; y nos lleva a identificar las diferentes competencias básicas para todos los ciudadanos y el rol del estudiante, expresadas por autores como son Majo y Marquès (2002); Marquès (2000); Cabero et al. (2003); Cabero (2000); Alva (2003); Sarramona (2004), Perrenoud (2004); Banco Mundial (2007); así como revisar investigaciones sobre competencias tecnológicas realizadas por Suárez, Almerich, Gargallo y Aliaga (2010); Cabero et al. (2006); Gallego (2007); López (2005); Cobo (2009); Cabero y Llorente (2006); Zabala (2002); Marquès (2008); Brito (2006); UNESCO (2008); Cabero, Llorente y Marín (2010); Prendes, Castañeda y Gutiérrez (2010); Ballesteros, Cabero, Llorente y Morales (2010); Guerra, González y García (2010); Gallego, Gámiz y Gutiérrez (2010); Cabero, Llorente y Puentes (2010), Universidad Metropolitana (2016).

Para conocer a fondo la carrera de Pedagogía en Venezuela, se revisa la formación de docentes en el país, encontrando que se inicia en 1870 con el presidente Guzmán Blanco. En el año de 1876 se fundan las Escuelas Normalistas que se responsabilizaron por la formación de maestros. En 1950 se creó el Instituto de Mejoramiento del Magisterio y desde 1953 en adelante, existen las carreras de Educación en la Universidad Central de Venezuela (UCV), Universidad de Los Andes (ULA), Universidad Católica Andrés Bello (UCAB), Universidad del Zulia (LUZ), Universidad Pedagógica Experimental Libertador (UPEL), Universidad Motropolitana (UNIMET), Universidad José María Vargas (UJMV), Universidad Monteávila (UMA), Universidad Experimental Simón Rodríguez (UNESR) entre otras. Para la presente investigación se logró el apoyo de seis universidades en la ciudad de Caracas, y nos focalizamos en las mismas. Estas fueron: 1) Universidad Central de Venezuela (UCV); 2) Universidad Pedagógica Experimental Libertador (UPEL); 3) Universidad José María Vargas (UJMV); 4) Universidad Católica Andrés Bello (UCAB); 5) Universidad Monteávila (UMA); y 6) Universidad Motropolitana (UNIMET). Algunas coincidencias encontradas en las seis instituciones en cuanto a la incorporación de las Tecnologías 
de la Información y la Comunicación en los planes de estudio tenemos que ofertan entre 0 a 5 asignaturas relacionadas, que se dan cursos utilizando alguna plataforma tecnológica, se tienen unidades o direcciones de soporte tecnológico, tienen un perfil del egresado de competencias genéricas, básicas y profesionales, entre las que se mencionan: 1. Manejo de las TIC, 2. Gestión de la información, 3. Habilidades para el uso de las TIC, 4. Diseña y construye recursos didácticos con el apoyo de la tecnología.

\section{METODOLOGÍA}

En relación a los aspectos metodológicos para el desarrollo del estudio se encuadra, siguiendo el análisis de las investigaciones sobre las competencias y las Tecnologías de la Información y la Comunicación, y de acuerdo con Hernández, Fernández \& Baptista (2006); Cabero y Llorente (2006); Arias (2006); Hurtado (2010); Salkind (1999); Bisquerra (2000) entre otros, en uno - "de campo""descriptivo" - "ex post facto" - "transversal".

Se realizan descripciones comparativas de las competencias necesarias para el uso de las TIC por estudiantes universitarios de la carrera de Pedagogía, entre diferentes grupos de personas (estudiantes, docentes y empleadores). El estudio se lleva a cabo en cuatro fases, en la primera se elaboró un inventario o listado de competencias, en la segunda se validó el inventario de competencias a través de un juicio de expertos utilizando como estrategia la Técnica Delphi, la tercera se desarrolló en dos fases, en donde se elaboraron tres cuestionarios dirigidos a docentes, empleadores y estudiantes, se sometieron a juicio de expertos y prueba piloto y se desarrolló la versión final de cada uno. Seguidamente se administraron cada uno de los cuestionarios a la población correspondiente. En la cuarta fase del estudio se realizó el tratamiento de los datos de los tres instrumentos, se analizaron para luego dar las conclusiones e implicaciones del estudio.

Como se ha mencionado, la población de estudio estaba configurada por: primero, estudiantes que cursen la carrera de Pedagogía en universidades públicas y privadas en la ciudad de Caracas, Venezuela. Segundo, docentes que dicten clases en la carrera de Pedagogía en universidades públicas y privadas en la ciudad de Caracas, Venezuela y tercero, empleadores de egresados de esta carrera en universidades públicas y privadas en la ciudad de Caracas, Venezuela. Dada la magnitud de la población se tomaron algunas decisiones, para el caso de los estudiantes resultaba importante lograr la mayor participación posible, por lo que no fue necesario extraer una muestra, sino que esta fue igual a la población. En el caso con los docentes y empleadores, se estableció una muestra intencional u opinática, ya que fueron escogidos con base a criterios o juicios preestablecidos por el investigador (Arias, 2006; Hernández et al., 2006). En este caso se buscaba la calidad en la muestra, más que en la cantidad. Fundamentado en estos planteamientos, la muestra dirigida o por conveniencia, quedo conformada por un panel de 40 especialistas, representantes de diferentes universidades e instituciones educativas, distribuidos entre veinte (20) docentes que dicten clases en la carrera de Pedagogía en universidades públicas y privadas en la ciudad de Caracas, Venezuela y veinte (20) 
empleadores de egresados de la carrera de Pedagogía en universidades públicas y privadas en la ciudad de Caracas, Venezuela. El perfil de los docentes se corresponde con profesores que dictan o coordinan asignaturas relacionadas con las TIC y que al menos tengan cinco (5) años de experiencia. Finalmente, al administrar los instrumentos se superó la meta establecida, logrando la participación de 29 docentes. Siendo estos la mayoría de sexo femenino (19), así como el 62\% tenía estudios de tercer y cuarto nivel. En el caso de los empleadores, el perfil se corresponde a un profesional que ejerce en una institución educativa (universidad, unidad educativa, centro de educación básica, preescolar, o inicial), en alguno de los cargos de director, subdirector, coordinador, decano, jefe de departamento. Un profesional que contrata o supervisa docentes egresados de las universidades participantes del estudio, y que en la institución educativa exista integración de las TIC (presencia de sala de cómputos o directamente en las aulas de clase) y que al menos tenga cinco (5) años de experiencia. En este caso también se logró mayor participación de la meta establecida, ya que el cuestionario lo respondieron treinta (30) empleadores, de los cuales 24 (80\%) eran de sexo femenino, el $46,7 \%$ (14) tienen título universitario de licenciado, y el $43,3 \%$ (13) poseen títulos de tercer y cuarto nivel. El perfil de los estudiantes son todos aquellos que cursaran la carrera de Pedagogía en cualquiera de sus menciones, en alguna universidad pública o privada, ubicada en la ciudad de Caracas, Venezuela, y que al menos hayan cursado la mitad de la carrera, teniendo preferencia por aquellos que estuvieran en los últimos períodos académicos. En general las edades de los estudiantes que participaron en el estudio fue entre los 18 a los 31 años o más, encontrando que más de la mitad, es decir el 55,8\% de estudiantes tenían entre 19 y 23 años, el $81 \%$ de sexo femenino, de las menciones de "Educación Preescolar" el 26,2\%, seguida de "Educación" el $21 \%$, "Ciencias Sociales" el 7,8\% y "Educación Integral" el 6,2\%, entre otras especialidades. En el siguiente cuadro se observa la distribución de la muestra por cada una de las poblaciones consultadas:

Tabla 1. Conformación de la muestra por Universidad / Docentes / Estudiantes.

\begin{tabular}{|c|c|c|c|c|c|c|c|}
\hline Universidad & UCAB & UCV & UNIMET & MONTEÁVILA & UPEL & UESR & Total \\
\hline Docentes & 5 & 3 & 3 & 3 & 9 & 6 & $\mathbf{2 9}$ \\
\hline Estudiantes & 86 & 96 & 50 & 18 & 88 & 47 & $\mathbf{3 8 5}$ \\
\hline
\end{tabular}

Fuente: Bello \& Morales (2011).

Tabla 2. Conformación de la muestra de Empleadores.

\begin{tabular}{|c|c|}
\hline Tipo de Institución & $\mathbf{N}^{\circ}$ Empleadores participantes \\
\hline Universidad & 4 \\
\hline Unidad Educativa & 10 \\
\hline Educación Básica & 2 \\
\hline Preescolar & 13 \\
\hline Otra & 1 \\
\hline Total & $\mathbf{3 0}$ \\
\hline
\end{tabular}

Fuente: Bello \& Morales (2011). 

Bello van der Ree, M. E. y Morales Lozano, J. A. Competencias claves de los estudiantes
universitarios para el uso de las TIC

Los cuestionarios diseñados son semiestructurados o mixtos (combinando preguntas en su mayoría cerradas y algunas abiertas), y fueron autoadministrados, utilizando diversas estrategias como correo electrónico, servicio de mensajería y entrega personal.

De acuerdo al resultado del juicio de expertos consultados el inventario quedo conformado por 54 competencias, como se puede observar en el siguiente cuadro:

Tabla 3. Inventario de competencias.

$\mathbf{N}^{\circ}$

1 Conocer el funcionamiento básico de un computador y sus periféricos.

2 Conectar un computador y sus periféricos: impresoras, scanner, teclado, mouse, cámaras, cornetas, micrófono.

3 Instalar y desinstalar programas informáticos en un computador.

4 Configurar el correo electrónico, tipo Microsoft Outlook, Eudora, Life Mail, Pegasus, entre otros.

5 Configurar un programa de antivirus, tipo Microsoft McAfee.

6 Utilizar el teclado y sus funciones básicas.

7 Escribir un documento con un procesador de palabras (Word, WordPerfect, Writer, entre otros).

Utilizar las funcionas avanzadas al escribir un documento en un procesador de palabras, como: cambiar el tipo y tamaño

8 de letra, insertar encabezado y pie de página, utilizar numeración y viñeta, dirección de texto, bordes y sombreados, entre otras.

9 Insertar tablas, gráficos o textos de otros documentos al utilizar un procesador de palabras.

10 Utilizar las funciones básicas, como la suma, productos o medias, en hojas de cálculo (Excel, Calc, Gnumeric, entre otras).

Utilizar otras funciones de las hojas de cálculo como son dar formato a las celdas, insertar y ocultar filas y columnas, autoajustar el tamaño de celdas, filas y columnas, entre otras.

12 Utilizar en las hojas de cálculo las funciones para crear formulas, insertar gráficos, imágenes e hipervínculos, entre otras.

13 Organizar la información utilizando herramientas como bases de datos, hojas de cálculo o programas similares.

14 Modificar imágenes y gráficos utilizando algún programa informático. (Photoshop, CorelDRAW, GIMP, etc.)

15 Crear clip de audio con algún programa informático.

16 Elaborar presentaciones multimedia (PowerPoint, Impress, entre otros) utilizando imágenes estáticas, textos, clip de audio o video, gráficos, etc.

17 Utilizar organizadores gráficos, tales como mapas conceptuales, diagramas o esquemas, para presentar las relaciones entre ideas o conceptos.

18 Navegar por Internet utilizando diferentes programas como: Explorer, Netscape, Mozilla, Opera, entre otros.

19 Utilizar los distintos links, enlaces o hipervínculos que aparecen en las páginas Web visitadas en Internet.

20 Diseñar páginas Web utilizando algún programa informático, por ejemplo Dreamweaver, FrontPage, entre otros.

21 Bajar de Internet programas, imágenes, clips de audio entre otros.

22 Participar en foros de discusión, ya sea como coordinador o participante.

23 Utilizar diferentes buscadores en Internet como son Google, Yahoo!, etc.

24 Utilizar las opciones "Avanzadas" de los buscadores en Internet.

25 Organizar la información encontrada en Internet a través de la función de "Favoritos" clasificándola en carpetas y/o subcarpetas.

26 Participar en video conferencias utilizando programas informáticos (NetMeeting, Messenger, Skype, etc.)

27 Encontrar información utilizando otras formas y formatos como son CD-ROM, DVD, vídeo, entre otros.

28 Establecer comunicación con otras personas utilizando software de trabajo colaborativo, como son el correo electrónico, Chat, mensajería instantánea, foros de distribución, Blogs, Wiki, entre otros.

29 Utilizar manuales de ayuda en línea.

30 Utilizar diferentes tipos de dispositivos de almacenamiento (discos, CD-ROM, Pendrive, Flashcard, entre otros).

31 Evaluar la autoría y fiabilidad de la información encontrada en Internet.

32 Conocer las fortalezas y limitaciones que presentan los computadores para almacenar, organizar, recuperar y seleccionar

32 información.

33 Juzgar y hacer aportaciones para mejorar las producciones multimedia realizadas por mis compañeros.

34 Discriminar con frecuencia correo electrónico con virus, basura o spam.

35 Establecer criterios de evaluación de las fuentes de información y de las herramientas de las TIC.

36 Realizar búsquedas bibliográficas a través de diferentes bases de datos disponibles en la red. 
Bello van der Ree, M. E. y Morales Lozano, J. A. Competencias claves de los estudiantes universitarios para el uso de las TIC

\begin{tabular}{|c|c|}
\hline $\mathbf{N}^{\circ}$ & INVENTARIO DE COMPETENCIAS \\
\hline 37 & $\begin{array}{l}\text { Utilizar la herramienta de idioma y corrector ortográfico, para editar y revisar su trabajo, a través de programas } \\
\text { informáticos como procesadores de textos, hojas de cálculo, presentaciones. }\end{array}$ \\
\hline 38 & $\begin{array}{l}\text { Conocer el vocabulario relacionado con las Tecnologías de Información y Comunicación (TIC, Hardware, Software, CD, } \\
\text { Internet, Búsqueda, CPU, hipertexto, etc.) }\end{array}$ \\
\hline 39 & $\begin{array}{l}\text { Diseñar recursos didácticos utilizando diferentes herramientas o programas como son procesadores de palabras, hojas de } \\
\text { cálculo y editores de presentaciones, entre otros. (Word, Excel, PowerPoint, etc.) }\end{array}$ \\
\hline 40 & Recuperar información utilizando diferentes fuentes (bibliotecas en línea, bases de datos, revistas electrónicas etc.) \\
\hline 41 & $\begin{array}{l}\text { Analizar la información recuperada a través de diferentes fuentes (bibliotecas en línea, bases de datos, revistas } \\
\text { electrónicas etc.) }\end{array}$ \\
\hline 42 & $\begin{array}{l}\text { Mantener una actitud crítica, de acuerdo a su sistema de valores, ante la información que recupera a través de las } \\
\text { Tecnologías de la Información y la Comunicación. }\end{array}$ \\
\hline 43 & $\begin{array}{l}\text { Tener capacidad crítica para enjuiciar la información, los recursos y servicios de tele documentación disponibles en la } \\
\text { Web. }\end{array}$ \\
\hline 44 & Participar en cursos relacionados a su carrera a través del sistema de enseñanza a distancia / e-learning. \\
\hline 45 & $\begin{array}{l}\text { Conocer los recursos electrónicos que son necesarios para la documentación pedagógica (URL, motores de búsqueda, } \\
\text { bases de datos, foros, weblogs, video-conferencia, etc.) }\end{array}$ \\
\hline 46 & $\begin{array}{l}\text { Aplicar los elementos de un diseño de instrucción para el desarrollo y evaluación de cursos bajo la modalidad a distancia / } \\
\text { e-learning. }\end{array}$ \\
\hline 47 & $\begin{array}{l}\text { Utilizar las funciones básicas de la hoja de cálculo en la práctica educativa (promedio de notas, elaboración instrumentos } \\
\text { de evaluación, entre otros). }\end{array}$ \\
\hline 48 & Desarrollar juegos digitales utilizando herramientas como PowerPoint, Flash, Director, entre otros. \\
\hline 49 & Buscar información relevante para su práctica pedagógica a través de las TIC. \\
\hline 50 & Evaluar y seleccionar software educativo para su práctica pedagógica. \\
\hline 51 & Diseñar actividades escolares asistidas por el ordenador. \\
\hline \multirow{5}{*}{52} & $\begin{array}{l}\text { Usar Internet y las TIC como herramienta para: } \\
\quad-\quad \text { Comunicarse. }\end{array}$ \\
\hline & $-\quad$ Investigar (actividad académica). \\
\hline & - $\quad$ Construir "productos" (informes, trabajos, presentaciones, etc.) \\
\hline & - $\quad$ Aprender. \\
\hline & - $\quad$ Obtener información (variada). \\
\hline 53 & $\begin{array}{l}\text { Crear materiales de instrucción utilizando diferentes programas, como son CorelDraw, Photoshop, Flash, Excel, } \\
\text { PowerPoint, Word, entre otros. }\end{array}$ \\
\hline 54 & Utilizar herramientas tecnológicas para la evaluación, auto-evaluación y co-evaluación \\
\hline
\end{tabular}

Fuente: Bello \& Morales (2011, pp. 354-355).

Los demás cuestionarios se organizaron en dos partes. En la primera se recogen aspectos generales que permitiera describir a la población, así como para indagar sobre aspectos relacionados a las Tecnologías de la Información y la Comunicación. La segunda parte quedo integrada con el inventario de las 54 competencias y para consultar las mismas se estableció una escala tipo Likert que buscó conocer la percepción de los docentes, empleadores y estudiantes en cuanto a la importancia y el desarrollo de cada competencia. La escala es de 1 a 4, en donde uno reflejaba una opinión desfavorable y cuatro la más favorable.

Posteriormente se recolectaron los datos logrando la participación de 30 empleadores, 29 docentes y 385 estudiantes. En resumen la construcción de instrumentos se resume en la siguiente imagen: 


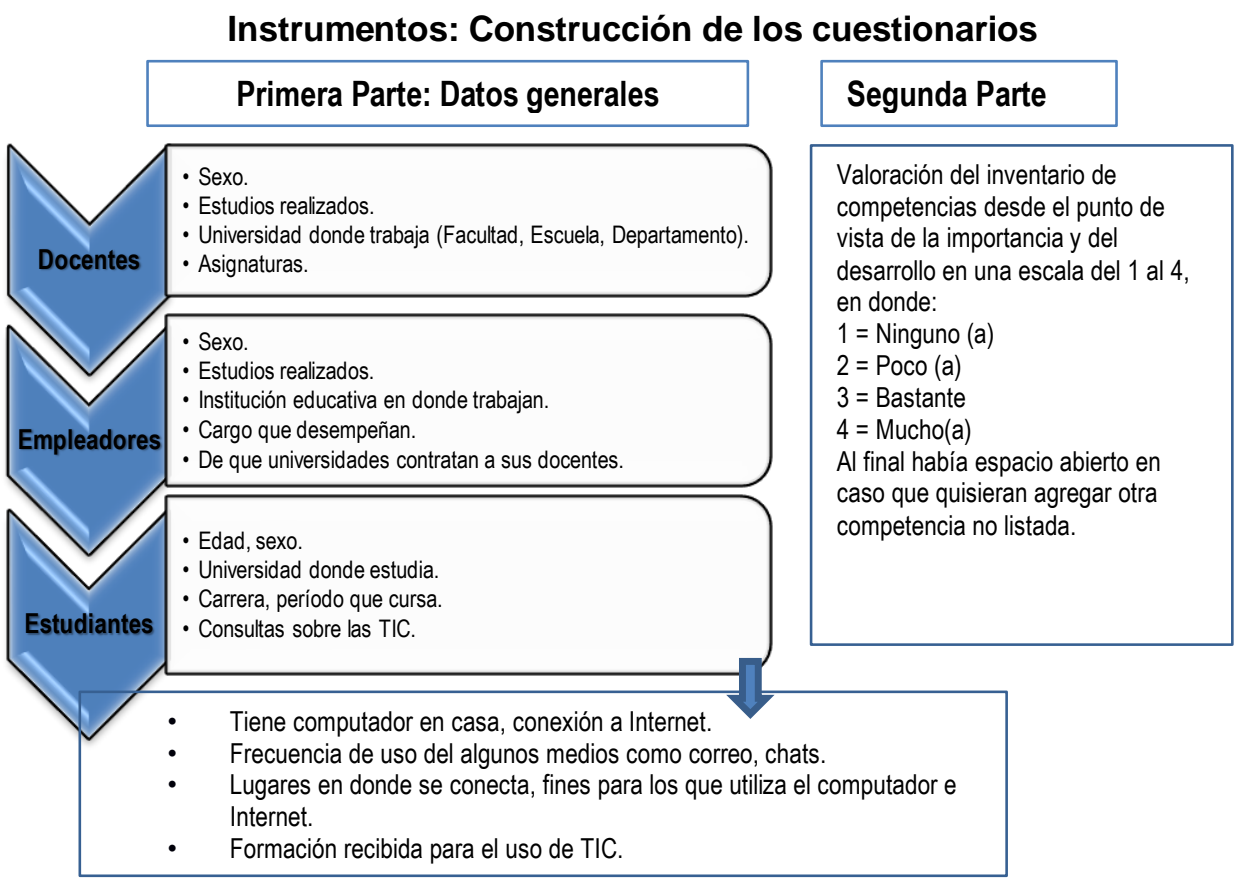

Figura 1: Instrumentos: Construcción de cuestionarios.

Fuente: Bello \& Morales (2011).

Para el análisis de los datos se utiliza un enfoque mixto, con la finalidad de describir competencias de los estudiantes para el uso de las Tecnologías de la Información y la Comunicación. Se utilizó estadística descriptiva, es decir, frecuencia y porcentaje, en la mayoría de las preguntas. También se realizaron contrastes entre los datos obtenidos de los diferentes grupos desde el nivel de importancia y desarrollo de las competencias con el interés si existía o no algún tipo de relación entre las mismas, por lo que se hace un análisis de correlación entre las tres poblaciones. Para las preguntas de carácter abierto se llevó a cabo un análisis de contenido de acuerdo a su relación con el marco teórico.

Los resultados se presentan de acuerdo a la operacionalización de las dimensiones principales del estudio, es decir, se describen por categorías apoyándose en el uso de gráficas y tablas para cada uno de los indicadores y preguntas a que se alude. De acuerdo con los objetivos planteados, se describen los resultados de cada uno de los cuestionarios utilizados, y se analizan las distinciones más importantes que se hayan encontrado según la muestra, para posteriormente triangular y comparar toda la información recolectada.

Las fases de la investigación fueron las siguientes: 
Bello van der Ree, M. E. y Morales Lozano, J. A. Competencias claves de los estudiantes universitarios para el uso de las TIC

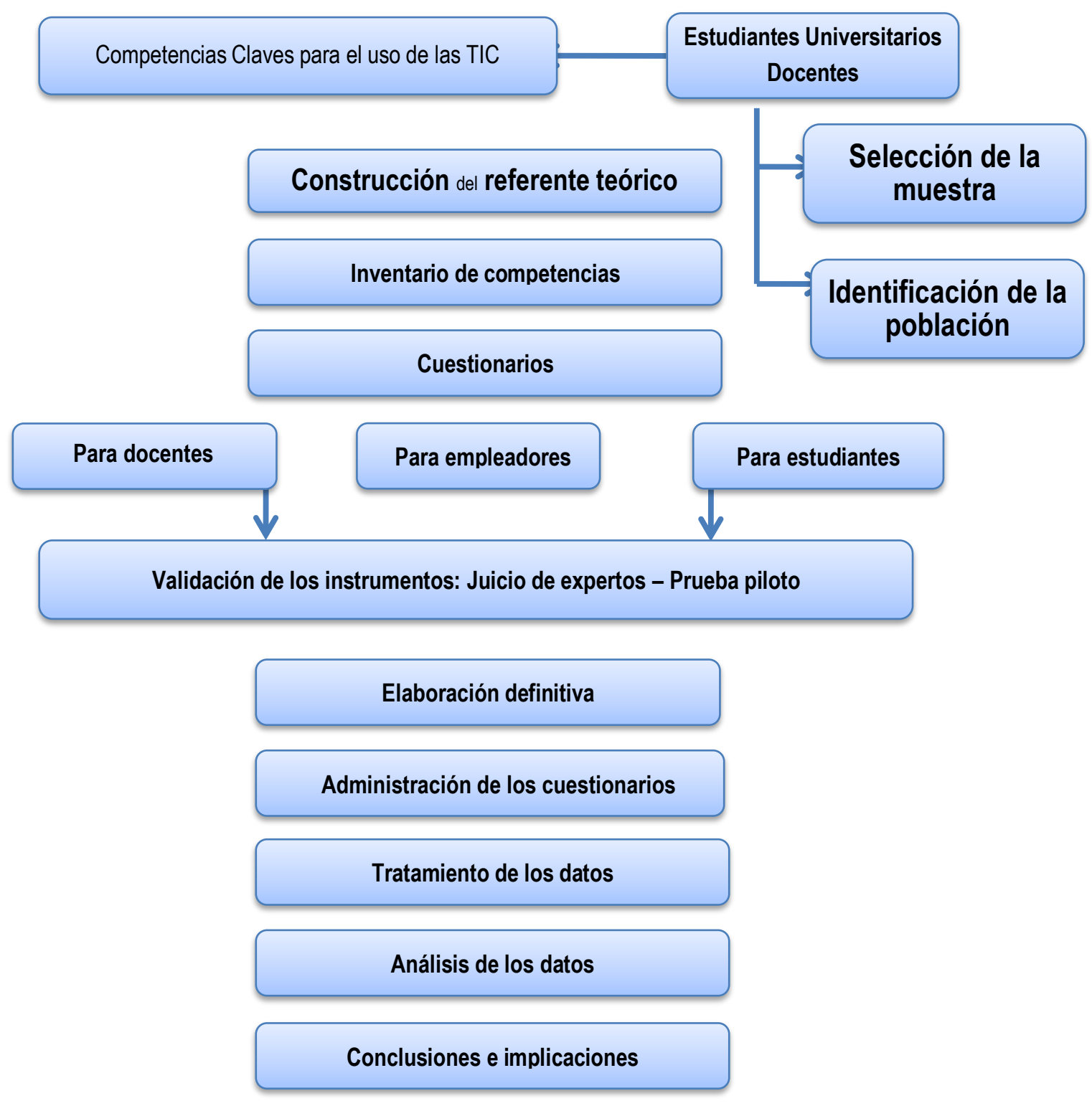

Figura 2: Fases de la investigación.

Fuente: Bello \& Morales (2011, p. 326).

\section{DISCUSIÓN}

Con la finalidad de poder contrastar y correlacionar los resultados obtenidos se presentan desde cuatro puntos de vista, en primer lugar, los generales que nos dieron información inicial de cada una de las poblaciones consultadas, especialmente para conocer sus hábitos y uso de las TIC. En segundo, se presentó en detalle lo obtenido de cada una de las poblaciones, describiendo de manera individual cada competencia desde el nivel de importancia y de desarrollo. En tercero se detallaron los resultados globalizados de acuerdo a las categorías de las competencias, con el fin de describir el nivel de importancia y de desarrollo, y luego se compararon los datos obtenidos de las diferentes poblaciones. En cuarto, se presentó el estudio de correlaciones a fin de determinar la relación o dependencia entre la importancia y el 
desarrollo de las categorías de las competencias estudiadas. En la siguiente imagen se observa lo mencionado:

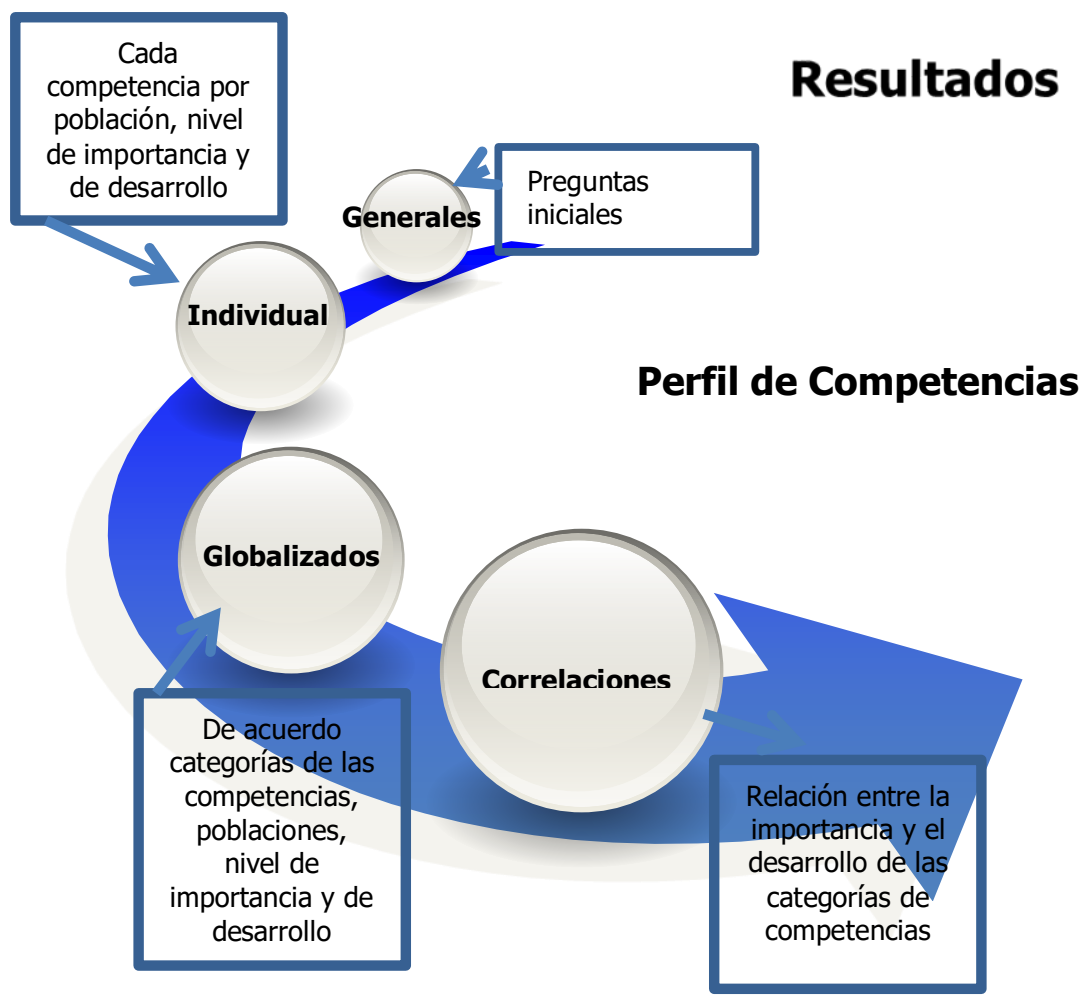

Figura 3: Análisis de los resultados.

Fuente: Bello \& Morales (2011).

A continuación se describen algunos de los resultados más relevantes de la investigación y a los fines de la publicación se hará énfasis en lo expresado por los estudiantes. Ante la pregunta si tenían conexión a Internet en la casa, doscientos treinta y dos (232) estudiantes respondieron que sí, mientras ciento cincuenta y tres (153) respondieron que no. Es decir un 60,25\% "Si" disponen de Internet mientras un 39\%, 75\% "No" tienen acceso al mismo. Esto indica que no todos los que tienen un computador desde su casa se conectan a Internet debido a que el porcentaje disminuye en este caso en 17 puntos, en otras palabras de 300 estudiantes que tienen computador en casa, solamente 232 se conectan a Internet desde su hogar. En Latinoamérica en el 2018 es del $66 \%$, cifra que coincide con los resultados del estudio. También nos señalan Contreras \& Campa (2017), que la mayoría de los estudiantes de secundaria en México prefieren socializar por medio de redes sociales la mayor parte de su tiempo, cuando no están en la escuela, los mismos adolescentes manifestaron estar siempre en contacto con sus compañeros de clase y amigos.

Hoy en día la población venezolana está más conectada debido a los teléfonos móviles, desde los cuales acceden a Internet y a la búsqueda de información de manera rápida, y a través del plan de datos al que estén afiliados. No podemos dejar 
de comentar que actualmente Venezuela, es uno de los países con menos libertades en el mundo, se ubica entre las tres naciones con peor conexión a Internet, con numerosas páginas bloqueadas, siendo esto un derecho humano declarado en el año 2011 por la Asamblea General de la Organización de Naciones Unidas (ONU) y su violación podría estar sujeta a sanciones penales internacionales (Martín, 2018). A los estudiantes se les consulta sobre la frecuencia de usos de diferentes medios, como son el computador, Internet, correo electrónico y chats en una escala que va desde diariamente a nunca. De acuerdo a las respuestas recibidas tenemos que en todos los casos la mayoría responden que los utilizan diariamente, obteniendo mayor puntaje el computador y el menor los chats, como podemos observar en la siguiente tabla:

Tabla 4. Frecuencia que utiliza los siguientes medios.

\begin{tabular}{|c|c|c|c|c|c|c|}
\hline Medios & Nunca & Ocasionalmente & $\begin{array}{c}\text { Una vez } \\
\text { cada 15 } \\
\text { días }\end{array}$ & $\begin{array}{c}\text { Una vez a } \\
\text { la semana }\end{array}$ & $\begin{array}{c}\text { Varias } \\
\text { veces a la } \\
\text { semana }\end{array}$ & Diariamente \\
\hline Computador & 0 & 22 & 2 & 6 & 79 & $\mathbf{2 7 6}$ \\
\hline Internet & 3 & 29 & 4 & 23 & 85 & $\mathbf{2 4 1}$ \\
\hline $\begin{array}{c}\text { Correo } \\
\text { electrónico }\end{array}$ & 2 & 31 & 9 & 32 & 85 & $\mathbf{2 2 6}$ \\
\hline Chats & 29 & 80 & 5 & 12 & 74 & $\mathbf{1 8 5}$ \\
\hline
\end{tabular}

Fuente: Bello \& Morales (2011, p. 373).

Cuando se le consulta a los estudiantes sobre los lugares en que suelen utilizar el computador $\mathrm{y} / \mathrm{o}$ Internet durante más tiempo encontramos que en todos las universidades el mayor porcentaje de respuestas fue en "Casa" con el 71,68\% (276 estudiantes), en segundo lugar "Cyber-café" con el 16,88\% (65 alumnos) y en tercero "Universidad" con el 5,97\% (23 estudiantes). El principal uso que hacen los estudiantes del computador es la de hacer los informes y trabajos de la universidad, seguido de escuchar música, ver películas o consultar información, hacer diseños y jugar. En cuanto al uso de Internet señalan que lo utilizan principalmente para buscar información necesaria para hacer sus trabajos, seguidamente para relacionarse con otros y hacer amistades, bajar música o películas y hacer cursos online. Los estudiantes consideran que han recibido formación para el uso de las TIC principalmente por la autoformación, seguido de la universidad y en Educación Media, señalando que califican su formación como buena.

Al consultar a los docentes sobre el nivel de importancia de las 54 competencias, consideran que más de los $83 \%$ como más significativas aquellas asociadas a navegar y a la búsqueda de información en Internet, seguido del uso básico de las herramientas como son las hojas de cálculo y el uso de internet para comunicarse, investigar, construir informes, aprender a obtener información variada. En cuanto al desarrollo de las competencias, señalan como muy y bastantes, las competencias 
relacionadas al uso de Internet y las TIC como herramienta para comunicarse, investigar, construir "productos" (informes, trabajos, presentaciones, etc.), aprender y obtener información variada ya que un promedio del $78,6 \%$ así lo expresan. Consideran que las competencias menos desarrolladas son aquellas asociadas con el instalar, desinstalar programas, configurar correo electrónico, conectar un computador, utilizar las funciones avanzadas de programas de hojas de cálculo.

Los empleadores expresaron que para ellos las competencias más importantes son escribir un documento, utilizar buscadores, navegar por Internet, encontrar información, usar dispositivos de almacenamiento. Como menos importantes consideran que son las relacionadas a desarrollar juegos digitales, bajar de Internet programas, imágenes, crear clip de audio. En cuanto al desarrollo de las competencias, las más relevantes son el escribir un documento, usar buscadores, manejar funciones avanzadas de un programa procesador de palabras como lo es Word, o utilizar la Red para buscar información. Las menos desarrolladas perciben que son el aplicar elementos de diseño de instrucción, desarrollar juegos digitales, participar en cursos a distancia y conocer recursos electrónicos para docentes.

Las tres poblaciones consideran como muy importante todo lo relacionado con el uso de Internet para aprender, investigar, comunicarse, construir documentos y conseguir información para la práctica pedagógica, el uso de procesadores de palabras, hojas de cálculo y editores de presentaciones. En cuanto a las menos importantes consideran que son aquellas relacionadas al diseño de páginas web, creación de un clip de audio, instalar o desinstalar programas, configuración de correos y programas anti-virus, conectar un computador. Llama la atención que empleadores y estudiantes colocan en los últimos lugares la participación en foros de discusión, y los estudiantes señalan el diseño de juegos digitales.

En relación al nivel de desarrollo de las competencias nuevamente las tres poblaciones perciben como muy avanzada la asociada a usar Internet para obtener información. Igualmente consideran como muy desarrolladas el uso de programas ofimáticos, especialmente en cuanto a sus funciones básicas. Las competencias asociadas a la comunicación e uso de herramientas para buscar información son consideradas por todos como bastante desarrolladas. En los últimos lugares, se tienen competencias asociadas al juzgar o valorar, así como capacidad crítica para aportar o mejorar. Se puede notar que hay coincidencias en cuanto a la importancia y nivel de desarrollo con competencias relacionadas con el diseño de páginas web, creación de clip de audio, configuración de programas de correo y antivirus, así como la instalar o desinstalar programas. Llama la atención que los estudiantes expresan tener poco desarrolladas competencias asociadas a educación a distancia/ e-learning, tanto en el diseño como participación, así como el desarrollo de juegos digitales. Se observaron coincidencias en cuanto al poco conocimiento que tienen los estudiantes de la carrera de Educación asociados a aspectos más técnicos, como es el hecho de instalar o desinstalar programas informáticos o la configuración del correo electrónico o de un programa antivirus. Preocupa el hecho que estén poco formados en cuanto a los elementos de un diseño de instrucción para el desarrollo de cursos a distancia, o el uso de recursos electrónicos para la documentación pedagógica. Se observa que 
posiblemente hay poco interés por conocer más a fondo herramientas como hojas de cálculo o programas para crear imágenes y gráficos como Photoshop, e uso de los manuales de ayuda en línea. Podría ser interesante revisar y/o recomendar que en los planes de estudio de las carreras de Educación se tomen en cuenta estos aspectos en donde hay coincidencia de poca o ninguna formación, especialmente en relación a las competencias asociadas al diseño de páginas web, creación de un clip de audio, y el desarrollo de juegos digitales utilizando herramientas como PowerPoint, Flash, Director, entre otros.

Otro paso seguido para analizar los datos obtenidos se organizaron las competencias en cinco categorías y se definieron cada una de ellas. Estas quedaron organizadas de la siguiente manera:

Tabla 5. Organización de las competencias en categorías.

\begin{tabular}{|c|l|}
\hline No & Categorías \\
\hline 1 & Sistemas informáticos (hardware, software, redes). \\
\hline 2 & Herramientas para la comunicación, información, investigación. \\
\hline 3 & Herramientas de productividad (programas, aplicaciones). \\
\hline 4 & $\begin{array}{l}\text { Utilidades de las TIC para el estudiante de Educación (diseño, evaluación, planificación, } \\
\text { desarrollo). }\end{array}$ \\
\hline 5 & Valoración que hace el estudiante de Educación sobre las TIC. \\
\hline
\end{tabular}

Fuente: Bello \& Morales (2011, p. 652).

Finalmente se consideró que era de interés para la investigación estudiar si existe o no algún tipo de relación entre la importancia, así como el desarrollo de las competencias de acuerdo a los resultados obtenidos de las respuestas de los docentes, empleadores y estudiantes. Para la presente investigación se utilizó el coeficiente de correlación lineal (cociente entre la covarianza y el producto de las desviaciones típicas de ambas variables). En las correlaciones entre la importancia y el desarrollo de las competencias desde el punto de vista de los docentes y estudiantes, se pudo observar que aparentemente no hay correlación entre lo que consideran importante y cuan desarrollada esta la competencia. La población de empleadores pareciera que están un poco más conscientes de lo útil e importante de las competencias, así como de su desarrollo, es decir se observan pequeñas correlaciones, lo cual pareciera que esta población está un poco más clara, se podría señalar que en el mundo laboral están más interesados tanto con la importancia como con el desarrollo de las TIC en la formación del docente venezolano. Al analizar los resultados obtenidos de la consulta a docentes, empleadores y estudiantes en cuanto a la importancia y desarrollo de las competencias para el uso de las TIC, de alguna manera se ve reflejado un aspecto de la cultura del venezolano en donde vive de acuerdo a su circunstancia el día a día. Esto se ve reflejado en investigaciones realizadas para conocer la personalidad del venezolano, una es el "Proyecto Pobreza" (Ugalde, España, Lacruz, De Viana, González, Luengo y Ponce, 2004), y otro es "Incidencia de la personalidad del venezolano en la determinación de nuevos segmentos de consumidores" (Cabrera, 2008). 
Bello van der Ree, M. E. y Morales Lozano, J. A. Competencias claves de los estudiantes universitarios para el uso de las TIC

\section{CONCLUSIONES}

Durante el desarrollo de la investigación se ha ido comprobando la importancia y papel relevante que han venido tomando en el mundo las Tecnologías de la Información y la Comunicación (TIC), especialmente en el área educativa en donde han tomado un papel relevante en la Educación Universitaria y especialmente en el diseño de programas y planes de estudio para la formación de docentes. En relación al objetivo sobre indagar las competencias que tienen los estudiantes universitarios de la carrera de Pedagogía para el manejo de las TIC. Encontramos que los estudiantes opinan que todas las competencias son relevantes, debido a que aproximadamente el $85 \%$ las puntúan en la mayor escala. Los estudiantes consideran que las cinco categorías de competencias son importantes, siendo la uno la que obtiene menos puntuación (Sistemas informáticos: hardware, software, redes). En cuanto al desarrollo de las competencias, los estudiantes tienen diversidad de opinión, ya que en general las perciben entre poco o bastantes desarrolladas. Casi la mitad de las mismas están marcadas en el nivel "4" y sumando los dos más altos niveles, se obtiene que aproximadamente 38 competencias las califican entre bastante y muy desarrolladas. En la siguiente tabla se resume la percepción de los estudiantes.

Tabla 6. Conclusiones estudiantes.

\begin{tabular}{|l|l|}
\hline Importancia & Desarrollo \\
\hline $85 \%$ competencias muy importantes. & $\begin{array}{l}38 \text { competencias entre bastante y muy } \\
\text { desarrolladas. }\end{array}$ \\
\hline $\begin{array}{l}\text { Menos importantes "Sistemas Informáticos: } \\
\text { hardware, software, redes". }\end{array}$ & $\begin{array}{l}\text { Mayor puntaje "Sistemas informáticos", } \\
\text { "Herramientas para la comunicación, } \\
\text { información e investigación" y "Herramientas } \\
\text { de productividad". }\end{array}$ \\
\hline $\begin{array}{l}\text { Más importantes "Herramientas de } \\
\text { productividad" Saber - Hacer. (Cabero et al., } \\
\begin{array}{l}\text { 2003a, Belloch, 2000, Cabero, 2006, Cabello y } \\
\text { Llorente, 2006). }\end{array}\end{array}$ & $\begin{array}{l}\text { Trabajar más: "Utilidades de las TIC" propias } \\
\text { para la práctica pedagógica (Cabero, 2006; } \\
\text { Cabero y Llorente, 2006; Fernández, 2006; } \\
\text { Cabero, 2008; UNESCO 2008; Cabero, Llorente } \\
\text { y Marín, 2010, entre otros). }\end{array}$ \\
\hline
\end{tabular}

Fuente: Bello \& Morales (2011).

En relación a la consulta que se realizó para conocer la opinión que tienen los docentes universitarios de la carrera de Pedagogía sobre las competencias que requieren los estudiantes para el uso de las TIC, en general expresan que consideran todas importantes, dando mayor puntuación a las categorías dos, es decir aquellas asociadas al uso de Internet, los links, enlaces o hipervínculos que aparecen en páginas web, utilizar los buscadores como Google, Yahoo!, etc., la comunicación con otras personas a través del correo electrónico, chat, mensajería instantánea, foros de discusión, blogs, entre otros. Es decir, en su mayoría aquellas correspondientes a las relacionadas con "Herramientas para la comunicación, información e investigación". En cuanto al desarrollo de las competencias nuevamente señalan con mayor puntuación las mismas competencias asociadas a la categoría dos, y las menos 
Bello van der Ree, M. E. y Morales Lozano, J. A. Competencias claves de los estudiantes universitarios para el uso de las TIC

trabajadas las asociadas a los sistemas informáticos. En la siguiente tabla se resumen las opiniones de los docentes.

Tabla 7. Conclusiones docentes.

\begin{tabular}{|l|l|}
\hline Importancia & Desarrollo \\
\hline Todas son importantes. & $\begin{array}{l}\text { Más desarrolladas: 78,6\% "Herramientas para } \\
\text { la comunicación, información e investigación". }\end{array}$ \\
\hline $\begin{array}{l}\text { Más importantes: "Herramientas para la } \\
\text { comunicación, información e investigación". }\end{array}$ & \begin{tabular}{l} 
Menos desarrolladas: "Sistemas informáticos". \\
\hline
\end{tabular} \\
$\begin{array}{l}\text { Poco desarrolladas: competencias asociadas } \\
\text { cursos a través de e-learning, conocer los } \\
\text { recursos electrónicos que son necesarios para } \\
\text { la documentación pedagógica y aplicar los } \\
\text { elementos de un diseño de instrucción para } \\
\text { cursos de modalidad a distancia (Cabero, 2006; } \\
\text { Cabero y Llorente, 2006; Fernández, 2006; } \\
\text { Cabero, Llorente y Marin, 2010, entre otros). }\end{array}$ \\
\hline
\end{tabular}

Fuente: Bello \& Morales (2011).

En relación al objetivo sobre explorar la opinión que tienen los empleadores en relación a las competencias que requieren los estudiantes egresados de la carrera de Pedagogía para el uso de las TIC, se percibe que en cuanto a la importancia un poco más del $67 \%$, consideran que 29 de las 58 competencias son muy relevantes. Al igual que las otras poblaciones también consideran las cinco categorías importantes, dando mayor puntuación a la dos, tres y cuatro. En cuanto al desarrollo, los empleadores presentan opiniones con una tendencia hacia bastante y poco desarrolladas las competencias. En la siguiente tabla se resumen sus opiniones.

Tabla 8. Conclusiones empleadores.

\begin{tabular}{|l|l|}
\hline Importancia & Desarrollo \\
\hline 29 competencias son muy relevantes. & Poco trabajadas: "Sistemas informáticos". \\
\hline $\begin{array}{l}\text { Más importantes: Herramientas de } \\
\text { Productividad y Herramientas para la } \\
\text { comunicación, información e investigación. }\end{array}$ & $\begin{array}{l}\text { Conocen y necesitan seguir trabajando: } \\
\text { "Herramientas de productividad" y valoración } \\
\text { que hacen de las TIC. }\end{array}$ \\
\hline & $\begin{array}{l}\text { Mejorar conocimiento: utilidades TIC que } \\
\text { permiten a los docentes el diseño, evaluación, } \\
\text { planificación de sus actividades pedagógicas. }\end{array}$ \\
& Mejorar formación de los docentes. \\
\hline
\end{tabular}

Fuente: Bello \& Morales (2011).

Cuando se comparan las percepciones desde el punto de vista de la importancia de cada una de las categorías de competencias, se observa que todas las

Revista de Comunicación de la SEECI. 15 noviembre, 2019 / 15 marzo, 2020, nº 50, 43-72 
poblaciones las consideran importantes, y se ordenan a continuación desde las de menor (abajo) hasta las de mayor importancia (arriba).

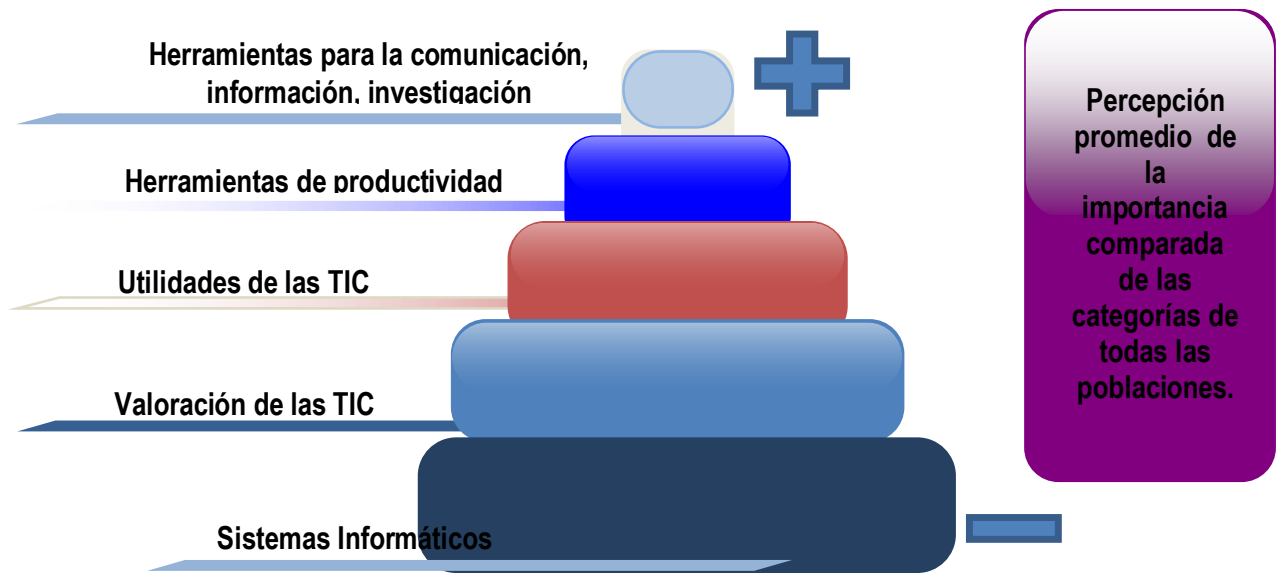

Figura 4: Nivel de importancia de las categorías.

Fuente: Bello \& Morales (2011).

Cuando se compara las percepciones desde el punto de vista del desarrollo se observa que hay diferencias de opiniones:

- Los docentes como los empleadores consideran como menos desarrollada la categoría "Sistemas informáticos (Hardware, software, redes)", en cambio para los estudiantes está categoría está entre "mucho" y "bastante" desarrollada.

- Las tres poblaciones opinan que conocen y necesitan seguir practicando las competencias asociadas a las utilidades de las TIC para el estudiante de Educación (diseño, evaluación, planificación, desarrollo) y la valoración que hace el estudiante de esta carrera sobre las TIC.

- Tanto los docentes como los estudiantes califican como mucho y bastante desarrolladas las competencias asociadas al uso de las herramientas para la comunicación, información, investigación, mientras los empleadores consideran que están entre bastante y poco trabajadas.

- En cuanto a las competencias sobre el uso de las herramientas de productividad (programas, aplicaciones), los docentes y empleadores consideran que está entre bastante y poco, mientras los estudiantes opinan que está muy desarrollada.

- Del estudio estadístico de correlaciones se obtiene que los resultados son coherentes en el sentido de que todos dicen exactamente lo mismo, y no hay correlaciones entre la importancia y el desarrollo de las competencias por parte de los estudiantes de la carrera de Pedagogía para el uso de las Tecnologías de la Información y la Comunicación (TIC).

En relación al estudio estadístico de correlaciones se obtiene que los resultados son coherentes en el sentido de que todos dicen exactamente lo mismo, y no hay correlaciones entre la importancia y el desarrollo de las competencias por parte de 
los estudiantes de la carrera de Pedagogía para el uso de las Tecnologías de la Información y la Comunicación (TIC).

A continuación y de acuerdo con el último objetivo específico de la investigación, se presenta propuesta del perfil de competencias claves que requiere el estudiante de la carrera de Pedagogía para el manejo de las Tecnologías de la Información y la Comunicación (TIC), el cual podría ser considerado en futuros diseños de planes de estudio y programas de formación de docentes, principalmente de universidades venezolanas:

Tabla 9. Perfil de competencias claves.

\begin{tabular}{|c|c|}
\hline \multicolumn{2}{|r|}{ Competencias } \\
\hline $\begin{array}{l}\text { 1. Capacidad para utilizar } \\
\text { las herramientas que } \\
\text { ofrecen las } \\
\text { Tecnologías de la } \\
\text { Información y la } \\
\text { Comunicación (TIC) } \\
\text { para comunicarse, } \\
\text { informarse e } \\
\text { investigar. }\end{array}$ & $\begin{array}{l}\text { a. Navegar por Internet utilizando diferentes programas como: Explorer, } \\
\text { Netscape, Mozilla, Opera, entre otros. } \\
\text { b. Utilizar los distintos links, enlaces o hipervínculos que aparecen en las } \\
\text { páginas Web visitadas en Internet. } \\
\text { c. Bajar de Internet programas, imágenes, clips de audio entre otros. } \\
\text { d. Participar en foros de discusión, ya sea como coordinador o } \\
\text { participante. } \\
\text { e. Utilizar diferentes buscadores en Internet como son Google, Yahoo!, } \\
\text { etc. } \\
\text { f. Utilizar las opciones "Avanzadas" de los buscadores en Internet } \\
\text { g. Participar en video conferencias utilizando programas informáticos } \\
\text { (NetMeeting, Messenger, Skype, etc.) } \\
\text { h. Establecer comunicación con otras personas utilizando software de } \\
\text { trabajo colaborativo, como son el correo electrónico, chat, mensajería } \\
\text { instantánea, foros de distribución, Blogs, Wiki, entre otros. } \\
\text { i. Utilizar los diferentes manuales de ayuda en línea, que ofrecen los } \\
\text { programas. } \\
\text { j. Realizar búsquedas bibliográficas a través de diferentes bases de } \\
\text { datos disponibles en la red. } \\
\text { k. Recuperar información utilizando diferentes fuentes (bibliotecas en } \\
\text { línea, bases de datos, revistas electrónicas etc.) } \\
\text { I. Participar en cursos relacionados a su carrera a través del sistema de } \\
\text { enseñanza a distancia / e-learning. } \\
\text { m. Usar Internet y las TIC como herramienta para: } \\
\text { i. Comunicarse. } \\
\text { ii. Investigar (Actividad Académica) } \\
\text { iii. Construir "productos" (informes, trabajos, presentaciones, etc.) } \\
\text { iv. Aprender. } \\
\text { v. Obtener información (variada). }\end{array}$ \\
\hline $\begin{array}{l}\text { 2. Capacidad para } \\
\text { producir documentos, } \\
\text { informes, } \\
\text { presentaciones, } \\
\text { material multimedia, } \\
\text { entre otras actividades } \\
\text { posibles utilizando las } \\
\text { Tecnologías de la } \\
\text { Información y la } \\
\text { Comunicación (TIC). }\end{array}$ & $\begin{array}{l}\text { a. Escribir un documento con un procesador de palabras (Word, } \\
\text { WordPerfect, Writer, entre otros), utilizando las funciones avanzadas } \\
\text { y otras como son Insertar tablas, gráficos o textos de otros } \\
\text { documentos al utilizar un procesador de palabras, o usar las } \\
\text { funciones básicas, como la suma, productos o medias, en hojas de } \\
\text { cálculo (Excel, Calc, Gnumeric, entre otras). } \\
\text { b. Organizar la información utilizando herramientas como bases de } \\
\text { datos, hojas de cálculo o programas similares. } \\
\text { c. Modificar imágenes y gráficos utilizando algún programa informático. } \\
\text { d. Crear clip de audio con algún programa informático. } \\
\text { e. Elaborar presentaciones multimedia (PowerPoint, Impress, entre } \\
\text { otros) utilizando imágenes estáticas, textos, clip de audio o video, } \\
\text { gráficos, etc. } \\
\text { f. Utilizar organizadores gráficos, tales como mapas conceptuales, } \\
\text { diagramas o esquemas, para presentar las relaciones entre ideas o } \\
\text { conceptos. } \\
\text { g. Encontrar información utilizando otras formas y formatos como son } \\
\text { hD-ROM, DVD, vídeo, entre otros. } \\
\text { h. Utilizar diferentes tipos de dispositivos de almacenamiento (discos, } \\
\text { CD-ROM, Pendrive, Flashcard, entre otros). }\end{array}$ \\
\hline 3. Capacidad para aplicar & a. Diseñar páginas web utilizando algún programa informático, por \\
\hline
\end{tabular}




\begin{tabular}{|c|c|}
\hline \multicolumn{2}{|r|}{ Competencias } \\
\hline $\begin{array}{l}\text { las diferentes } \\
\text { utilidades que ofrecen } \\
\text { las Tecnologías de la } \\
\text { Información y la } \\
\text { Comunicación (TIC) } \\
\text { para el desarrollo de } \\
\text { sus actividades } \\
\text { pedagógicas, tales } \\
\text { como el diseño de } \\
\text { programas, de } \\
\text { recursos didácticos, de } \\
\text { planificaciones, entre } \\
\text { otras posibilidades. }\end{array}$ & $\begin{array}{l}\text { ejemplo Dreamweaver, FrontPage, entre otros. } \\
\text { b. Diseñar recursos didácticos utilizando diferentes herramientas o } \\
\text { programas como son procesadores de palabras, hojas de cálculo y } \\
\text { editores de presentaciones, entre otros (Word, Excel, PowerPoint, } \\
\text { etc.) } \\
\text { c. Conocer los recursos electrónicos que son necesarios para la } \\
\text { documentación pedagógica (URL, motores de búsqueda, bases de } \\
\text { datos, foros, weblogs, video-conferencia, etc.) } \\
\text { d. Aplicar los elementos de un diseño de instrucción para el desarrollo y } \\
\text { evaluación de cursos bajo la modalidad a distancia / e-learning. } \\
\text { e. Utilizar las funciones básicas de la hoja de cálculo en la práctica } \\
\text { educativa (promedio de notas, elaboración instrumentos de } \\
\text { evaluación, entre otros). } \\
\text { f. Desarrollar actividades y/o juegos digitales asistidos por el } \\
\text { computador, utilizando herramientas como PowerPoint, Flash, } \\
\text { Director, entre otros. } \\
\text { g. Seleccionar software educativo para su práctica pedagógica. } \\
\text { h. Crear materiales de instrucción utilizando diferentes programas, como } \\
\text { son CorelDRAW, Photoshop, Flash, Excel, PowerPoint, Word, entre } \\
\text { i. } \begin{array}{l}\text { otros. } \\
\text { Utilizar herramientas tecnológicas para la evaluación, auto-evaluación } \\
\text { y co-evaluación. }\end{array}\end{array}$ \\
\hline $\begin{array}{l}\text { 4. Capacidad para } \\
\text { valorar los beneficios } \\
\text { que ofrecen las } \\
\text { Tecnologías de la } \\
\text { Información y la } \\
\text { Comunicación en la } \\
\text { práctica pedagógica } \\
\text { de los docentes. }\end{array}$ & $\begin{array}{l}\text { a. Evaluar la autoría y fiabilidad de la información encontrada en } \\
\text { Internet. } \\
\text { b. Conocer las fortalezas y limitaciones que presentan los computadores } \\
\text { para almacenar, organizar, recuperar y seleccionar información. } \\
\text { c. Juzgar haciendo aportes para mejorar las producciones multimedia } \\
\text { realizadas por mis compañeros. } \\
\text { d. Establecer criterios de evaluación de las fuentes de información y de } \\
\text { las herramientas de las TIC. } \\
\text { e. Analizar la información recuperada a través de diferentes fuentes } \\
\text { (bibliotecas en línea, bases de datos, revistas electrónicas etc.) } \\
\text { f. Mantener una actitud crítica, de acuerdo a su sistema de valores, } \\
\text { ante la información que recupera a través de las Tecnologías de la } \\
\text { Información y la Comunicación. }\end{array}$ \\
\hline $\begin{array}{l}\text { 5. Capacidad para } \\
\text { conocer el } \\
\text { funcionamiento del } \\
\text { computador y } \\
\text { periféricos, instalar, } \\
\text { desinstalar y } \\
\text { configurar programas } \\
\text { informáticos, así como } \\
\text { el conocimiento del } \\
\text { vocabulario } \\
\text { relacionado con las } \\
\text { Tecnologías de la } \\
\text { Información y la } \\
\text { Comunicación (TIC). }\end{array}$ & $\begin{array}{l}\text { a. Conocer el funcionamiento básico de un computador y sus periféricos } \\
\text { b. Conectar un computador y sus periféricos: impresoras, scanner, } \\
\text { teclado, mouse, cámaras, cornetas, micrófono. } \\
\text { c. Instalar y desinstalar programas informáticos en un computador. } \\
\text { d. Configurar el correo electrónico, tipo Microsoft Outlook, Eudora, Life } \\
\text { e. Mail, Pegazus, entre otros. } \\
\text { f. Utilizar el teclado y sus funciones básicas } \\
\text { g. Conocer el vocabulario relacionado con las Tecnologías de la } \\
\text { Información y la Comunicación (TIC, Hardware, Software, CD, } \\
\text { Internet, Búsqueda, CPU, hipertexto, etc.) }\end{array}$ \\
\hline
\end{tabular}

Fuente: Bello \& Morales (2011).

\section{REFERENCIAS}

Aguaded, J. y Cabero, J. (2002). Educar en Red. Internet como recurso para educación. En Correa, R.: Búsqueda de Información en Internet (pp. 83-100). En Valverde, J., Herramientas de Comunicación sincrónica y asincrónica (pp. 57-81). Málaga: Ediciones Aljibe. 
Bello van der Ree, M. E. y Morales Lozano, J. A. Competencias claves de los estudiantes universitarios para el uso de las TIC

Aguaded, I. \& Contín, S. (Compiladores); Correa, R.; Amor, M.; Guzmán, M.; Merino, S.; y Bautista, J. (2002). Jóvenes, aulas y medios de comunicación. Propuestas y prácticas mediáticas para el aula. Argentina: Ediciones Ciccus-La Crujía.

Aguilar, M. et al. (2007). Las Tecnologías de Información y Comunicación: Retos y propuestas para la didáctica. En Bello, M. Las Tecnologías de Información y Comunicación y su práctica pedagógica: Estrategias de integración (pp. 13 - 25). Caracas: Universidad Metropolitana.

Alfonso, I. (2016). La Sociedad de la Información, Sociedad del Conocimiento y Sociedad del Aprendizaje. Referentes en torno a su formación. Bibliotecas. Anales de la Investigación, 12(2), 235-243. Recuperado de https://dialnet.unirioja.es/servlet/articulo?codigo $=5766698$

Alva, M. (2003). Las Tecnologías de la información y el nuevo paradigma educativo. Revista Digital de Educación y Nuevas Tecnologías Contexto Educativo, 5(28), Recuperado de http://contexto-educativo.com.ar/2003/5/nota-03.htm

Andrade, H. y Gómez, L. (2007). Tecnología Informática en la Escuela. Colombia: División Editorial y de Publicaciones UIS (Universidad Industrial de Santander).

Area, M. (2004). Los medios y las Tecnologías en la Educación. Madrid: Ediciones Pirámide (Grupo Anaya, S. A.).

Arias, F. (2006). El Proyecto de Investigación. Introducción a la metodología científica. Caracas, Venezuela: Editorial Episteme, C. A.

Ballesteros, C.; Cabero, J.; Llorente, M. C. y Morales, J. A. (2010). Usos del Elearning en las universidades andaluzas: estado de la situación y análisis de buenas prácticas. Píxel-Bit, Revista de Medios y Educación, (37), 7-18. Recuperado de http://www.sav.us.es/pixelbit/pixelbit/articulos/n37/1.html

Banco Mundial (2007). Ampliar oportunidades y construir competencias para los jóvenes. Una agenda para la educación secundaria. Colombia: Editorial Nomos, S. A.

BBC Mundo (2018). Los avances en la ciencia y la tecnología que podrían cambiar nuestras vidas en 2018. Recuperado de https://www.bbc.com/mundo/noticias$\underline{42526091}$

Belando-Montoro, M. R. (2017). Aprendizaje a lo largo de la vida. Concepto y componentes. Revista Iberoamericana de Educación, (75), 219-234. doi: https://doi.org/https://doi.org/10.35362/rie7501255

Bello, M. y Morales, J. (2007). Necesidades de Formación en el uso de las Nuevas Tecnologías de Información y Comunicación de Estudiantes Universitarios en Educación, Universidad Metropolitana. (Tesina inédita del doctorado). Universidad de Sevilla. España. 
Bello van der Ree, M. E. y Morales Lozano, J. A. Competencias claves de los estudiantes universitarios para el uso de las TIC

Bello, M. y Morales, J. (2011). Competencias Claves de los Estudiantes Universitarios para el uso de las Tecnologías de Información y Comunicación. (Tesis Doctoral inédita). Universidad de Sevilla. España.

Belloch, C. (2000) Recursos Tecnológicos en Educación y Logopedia. Recuperado de http://www.uv.es/ bellochc

Bisquerra, R. (2000). Métodos de investigación educativa. Guía práctica. Barcelona: Ceac.

Brito, V. (2006). Plan Integral para la Incorporación de las Tecnologías de Información y Comunicación en los Procesos de Formación de Alumnos y Docentes de la Escuela de Humanidades y Educación de la Universidad de Oriente. EDUTEC2005. Recuperado de http://www.ciedhumano.org/files/CongresoEDUTEC05/CONGRESOEDUTEC05IPUB L.html

Cabero, J.; Salinas, J.; Duarte, A. y Domingo, J. (2000). Nuevas Tecnologías Aplicadas a la Educación. En: Cabero, J. Las nuevas tecnologías de la información y comunicación: aportaciones a la enseñanza (pp. 15-37). En: Duarte, A. Los materiales hipermedias y multimedias aplicados a la enseñanza (pp. 137-158). Madrid: Síntesis, S. A.

Cabero, J. (2000). Uso de los medios audiovisuales, informáticos y las nuevas tecnologías en los centros andaluces. Universidad de Sevilla. Recuperado de http://tecnologiaedu.us.es/bibliovir/publica0.htm

Cabero, J. (2001). Tecnología Educativa. Diseño y utilización de medios en la enseñanza. Barcelona: Paidós.

Cabero, J. (2003). La utilización de las TIC, nuevos retos para las universidades. (ES.1.40) Universidad de Sevilla. España. Recuperado de http://tecnologiaedu.us.es/bibliovir/pdf/ES140.pdf

Cabero, J. (Dir.); Castaño, C.; Cebreiro, B.; Gisbert. M.; Martínez, F.; Morales, J.; Prendes, M.; Romero, R. y Salinas, J. (2002). Las TICs en la Universidad. Sevilla: Editorial MAD, S.L.

Cabero, J. et al. (2003). Las Nuevas Tecnologías en la actividad universitaria. PíxelBit. Revista de Medios y educación, (20), 81-100. Recuperado de http://tecnologiaedu.us.es/bibliovir/pdf/nnttact.pdf

Cabero, J.; LLorente, M. (Dirs.); Castaño, C. et al. (2006). La rosa de los vientos. Dominios tecnológicos de las TICs por los estudiantes. Universidad de Sevilla. España: Grupo de Investigación Didáctica. 
Bello van der Ree, M. E. y Morales Lozano, J. A. Competencias claves de los estudiantes universitarios para el uso de las TIC

Cabero, J. (2006). Estrategias para la formación del profesorado en TIC. EDUTEC205. Recuperado de http://www.ciedhumano.org/files/Edutec2005 jULIO.pdf

Cabero, J. (2007). Las necesidades de las TIC en el Ámbito Educativo: oportunidades, riesgos y necesidades. Recuperado de http://investigacion.ilce.edu.mx/tyce/45/articulo1.pdf

Cabero, J. (2008). Estrategias para la formación del profesorado en TIC. Blog sobre innovación docente. Facultad de Comunicación, Universidad de Sevilla. Recuperado de http://fcom.us.es/blogs/innovaciondocente/2008/09/29/estrategias-para-laformacion-del-profesorado-en-tic-julio-cabero-2/

Cabero, J. y Gisbert, M. (2008). La formación en Internet. Guía para el diseño de materiales didácticos. Colombia: Cooperativa Editorial Magisterio.

Cabero, J.; Llorente, M. y Marín, V. (2010). Hacia el diseño de un instrumento de diagnóstico de competencias tecnológicas del profesorado universitario. Revista Iberoamericana de Educación, 52(7). Recuperado de http://www.rieoei.org/deloslectores/3358Cabero.pdf

Cabero, J. et al. (2009). WEB.2 El uso de la Web en la sociedad del conocimiento. Investigación e implicaciones educativas. En Cabero, J. Educación 2.0 ¿Marca, moda o nueva visión de la Educación? (pp. 9-30). En Rodríguez, M. Wikis, su uso en educación. (pp. 131-147). En Fonseca, M., Edublogs: Blog's para Educar (pp. 81-110). Caracas: Universidad Metropolitana.

Castañon, N. y Aguilar, M. (2017). Análisis comparativo de las políticas públicas en tecnología educativa. Vivat Academia Revista de Comunicación, (140), 1-15. doi: doi.org/10.15178/va.2017.140.1-15 Recuperado de http://www.vivatacademia.net/index.php/vivat/article/view/1030/1215

Chan, M. (2005). Competencias mediacionales para la educación en línea. Revista Electrónica de Investigación Educativa, 72). Recuperado de http://redie.uabc.mx/vol7no2/contenido-chan.html

Cobo, J. (2009). Strategies to Promote the Development of E-competencies in the Next Generation of Professionals: European and International Trends. Monograph, (13). Recuperado de http://www.skope.ox.ac.uk

Contreras, R. y Campa, R. (2017). Caracterización del perfil de los estudiantes de secundarias en el acceso y uso de Internet a partir de las TIC. EDUTEC. Revista Electrónica de Tecnología Educativa, (61). Recuperado de http://www.edutec.es/revista/index.php/edutec-e/article/view/941

Curci, R et al. (2016). Hacia una conceptualización de las competencias en la Unimet. Recuperado de http://cort.as/-RFFX 
Bello van der Ree, M. E. y Morales Lozano, J. A. Competencias claves de los estudiantes universitarios para el uso de las TIC

Duarte, A. (2002). Nuevas Tecnologías, nuevos lenguajes. Las Nuevas Tecnologías Aplicadas a la Educación: Nuevos retos para la formación. Recuperado de http://tecnologiaedu.us.es/nuevosretos/ponencias/anaduarte.htm

El Universal (2015). Penetración de Internet en Venezuela supera 61\%, 18 de noviembre de 2015. Recuperado de

http://www.eluniversal.com/economia/151118/penetracion-de-internet-envenezuela-supera-61

Gallego, D. et al. (2007). El docente y las TIC: presente y futuro. Informe EDUCARED 2007. En: IV Congreso Internacional de EDUCARED. Fundación Telefónica. Recuperado de http://www.educared.net/congresoiv/documentacion informes01.html

Gallego, M.; Gámiz, V. y Gutiérrez, E. (2010). El futuro docente ante las competencias en el uso de las Tecnologías de la Información y Comunicación para enseñar. EDUTEC. Revista Electrónica de Tecnología Educativa, (34). Recuperado de http://edutec.rediris.es/Revelec2/revelec34/pdf/Edutec e n34 Gallego Gamiz Gu tierrez.pdf

García, E. y Lorente, R. (2017). De receptor pasivo a protagonista activo del proceso de enseñanza-aprendizaje: redefinición del rol del alumnado en la Educación Superior. Opción, 33(84), 120-153. Recuperado de http://www.redalyc.org/pdf/310/31054991006.pdf

García, J.; Tobón, S. y López, N. (2009). Currículo, didáctica y evaluación por competencias. Análisis desde el enfoque socioformativo. Caracas: Universidad Metropolitana.

García, M.; Reyes, J. y Godínez, G. (2017). Las TIC en la educación superior, innovaciones y retos. Revista Iberoamericana de las Ciencias Sociales y Humanísticas, 6(12). doi: https://doi.org/10.23913/ricsh.v6i12.135. Recuperado de https://dialnet.unirioja.es/servlet/articulo?codigo $=6255413$

Govantes, A. (2001). Retos y posibilidades que imponen las nuevas tecnologías de la información y las comunicaciones a la educación en los países del tercer mundo. Revista Digital de Educación y Nuevas Tecnologías Contexto Educativo, III(16). Recuperado de http://contexto-educativo.com.ar/2001/2/nota-04.htm

Guerra, S., González, N. y García-Ruiz, R. (2010). Utilización de las TIC por el profesorado universitario como recurso didáctico. Comunicar, (35), 141-148. doi: https://doi.org/10.3916/C35-2010-03-07

Hernández, R.; Fernández, C. y Baptista, P. (2006). Metodología de la Investigación. México: McGraw-Hill. 
Bello van der Ree, M. E. y Morales Lozano, J. A. Competencias claves de los estudiantes universitarios para el uso de las TIC

EDUCAUSE (2017). 2017 Horizon Report. Recuperado de https://www.nmc.org/publication/nmc-horizon-report-2017-higher-educationedition-spanish/

Hurtado, J. (2010). El proyecto de investigación. Comprensión holística de la metodología y la investigación. Caracas-Bogotá: Ediciones Quirón.

Ibáñez, J. (2003). El uso educativo de las TIC. Recuperado de http://www.pangea.org/jei/edu/f/tic-uso-edu.htm\# Toc50017385

Jiménez, C. (20015). Tendencias Digitales, 2015. Recuperado de http://tendenciasdigitales.com/7-tendencias-digitales-para-el-2015/

Joa, C. (2003). Gestión de FUNDABIT para la apropiación de las Tecnologías de la Información y la Comunicación en las comunidades educativas. En Edutec - 2003. U.C.V.: Caracas.

López, A. (2001). Son Un Peligro las NTIC? Problemas Socioeconómicos, Políticos, Culturales y Éticos Parte I. Contexto educativo revista digital de investigación y nuevas tecnologías, III(49). Recuperado de http://contextoeducativo.com.ar/2001/5/nota-10.htm

López De Tkachenko, G. (2005). Competencias del docente para el Siglo XXI. Universitas 2000, 29(1-2). 115-131. Recuperado de http://www2.scielo.org.ve/scielo.php?script=sci arttext\&pid=S1315$\underline{41192005000100006 \& \operatorname{lng}=e s \& n r m=i s o}$

Majo, J. y Marquès, P. (2002). La revolución educativa en la era Internet. Barcelona: CISSPRAXIS, S.A.

Marquès, P. (2000). Las TIC y sus aportaciones a la sociedad. Recuperado de http://dewey.uab.es/pmarques/tic.htm. Consultado el 15/07/2004

Marquès, P. (2008). Los formadores ante la sociedad de la información. Recuperado de http://peremarques.pangea.org/docentes.htm

Martín, S. (2018). Venezuela, el país con peor conexión a internet en América Latina. Publicado en Panam Post, noticias y análisis de las Américas el 19 de noviembre de 2018. Recuperado de https://es.panampost.com/sabrinamartin/2018/11/19/venezuela-el-pais-con-peor-conexion-a-internet-en-americalatina/?cn-reloaded $=1$

Martínez, R-O-A; Pérez, H.; Granda, E. y Sanpedro, A. (2002). Evaluación de las necesidades de los estudiantes universitarios en el uso de las tecnologías de la información y la comunicación (TIC) como recursos para el aprendizaje. En conferencia: Virtual Educa 2002. Recuperado de http://www.virtualeduca.net/html/princip2.htm 
Bello van der Ree, M. E. y Morales Lozano, J. A. Competencias claves de los estudiantes universitarios para el uso de las TIC

Morales, E.; García, F.; Campos, R. y Astroza, C. (2013). Desarrollo de competencias a través de objetos de aprendizaje RED. Revista de Educación a Distancia, (36), 1-19. Recuperado de http://www.redalyc.org/articulo.oa?id=54725668005

Morales, J. A. (2010). Espacio europeo de Educación y Formación Profesional. Formación XXI. Revista de Formación y Empleo. Recuperado de http://formacionxxi.com/porqualMagazine/do/get/magazineArticle/2010/07/text/x $\mathrm{ml} /$ Espacio europeo de Educacion y Formacion Profesional.xml.html

Ojeda, M; Rosa-Pino, M. y Soto, J. (2017). Importancia de las competencias instrumentales en formación de docentes para educación secundaria. Universidad de Vigo. Revista de estudios e investigación en psicología y educación, Vol. Extr.(6). doi: https://doi.org/10.17979/reipe.2017.0.06.2676

Parra, E. (2003). Sistemas tutoriales inteligentes, una porte de la inteligencia artificial para la mediación pedagógica. U-ZINE. Recuperado de http://www.ucn.edu.co/uzine/Volumen12/Articulos/art 1.htm

Perrenoud, P. (2004). Diez nuevas competencias para enseñar. Barcelona: Editorial GRAÓ.

Prendes, M. P., Castañeda, L. y Gutiérrez, I. (2010). Competencias para el uso de TIC de los futuros maestros. Comunicar, XVIII(35), 175-182. Recuperado de http://www.revistacomunicar.com/index.php?contenido=detalles\&numero=35\&art iculo $=35-2010-21$

Romero, R. (2008). Nuevas tecnologías en educación infantil. El rincón del ordenador. Colombia: Cooperativa Editorial Magisterio.

Salkind, N. (1999). Métodos de Investigación. México: Prentice Hall.

Sarramona, J. (2004). Las competencias básicas en la educación obligatoria. España: Ediciones CEAC.

Sevillano, M. (2002). Nuevas Tecnologías, Medios de Comunicación y Educación. Formación Inicial y permanente del profesorado. Madrid: Editorial CCS.

Suárez, J. M.; Almerich, G.; Gargallo, B. \& Aliaga, F. (2010). Las competencias en TIC del profesorado y su relación con el uso de los recursos tecnológicos. Archivos Analíticos de Políticas Educativas, 18(10). Recuperado de http://epaa.asu.edu/ojs/article/view/755

Tendencias Digitales (2019). Consumo de medios en un mundo móvil. Recuperado de https://tendenciasdigitales.com/consumo-de-medios-en-un-mundo-movil/

UNESCO (2008). Estándares de Competencias en TIC para Docentes. Recuperado de http://tecnologiaedu.us.es/nweb/htm/bibliovir-docs-5.asp 
Bello van der Ree, M. E. y Morales Lozano, J. A. Competencias claves de los estudiantes universitarios para el uso de las TIC

Zabala, M. (2002). La enseñanza universitaria. El escenario y sus protagonistas. Madrid: Ed. NANCEA.

\section{AUTORES:}

\section{María Eugenia Bello van der Ree}

Doctora en Didáctica y Organización de Instituciones Educativas de la Universidad de Sevilla, España. Maestría en Educación de niños pequeños en la Universidad de Stanford, Estado Unidos y Licenciada en Educación, mención Ciencias Pedagógicas de la Universidad Católica Andrés Bello, Venezuela. Trabaja en la Universidad Metropolitana en Caracas, Venezuela desde 1982, como profesora por horas y desde el año 2000 como docente a tiempo completo en el Departamento de Ciencias de la Educación, ha desempeñado cargos de gerente académico como Coordinadora de la Especialización en Gerencia de Instituciones Educativas, Directora de la Escuela de Educación y actualmente Decana de Formación General y Básica. Profesora a tiempo parcial en la Universidad Católica Andrés Bello, Escuela de Educación, desde 1999. mabello@unimet.edu.ve

Orcid ID: http://orcid.org/0000-0002-2183-7542

ResearchGate: https://www.researchgate.net/profile/Maria Bello8

\section{Juan Antonio Morales Lozano}

Juan Antonio Morales Lozano: Catedrático de Universidad adscrito al Departamento de Didáctica y Organización Educativa de la Universidad de Sevilla. Miembro del Grupo de Investigación Didáctica (Plan Andaluz de Investigación: HUM390). Actividad docente en estudios de Grado (Maestro y Pedagogía), Máster (Dirección, Evaluación y Calidad de Instituciones Educativas y en Formación y Orientación para el Trabajo) y Doctorado en Educación.

jamorales@us.es

Orcid ID: https://orcid.org/0000-0003-1462-233X

Researcher Id: http://www.researcherid.com/rid/E-6114-2012

ScopusID: https://www.scopus.com/authid/detail.uri?authorId=36020200800

Dialnet: https://dialnet.unirioja.es/servlet/autor?codigo $=254115$

Más información en: http://investigacion.us.es/sisius/sis showpub.php?idpers=1950 